\title{
A desordem da oprdem no Sacramento da Penitência
}

\section{The disorder of the order in the Sacrament of Penance}

\author{
Luis Felipe C. Marques* \\ ISB
}

Recebido em: 16/09/2020. Aceito em: 21/10/2020.

Resumo: O presente artigo procura fazer uma abordagem da crise do sacramento da penitência de maneira interna, ou seja, apresenta que a crise deste sacramento encontra-se com a crise do sacramento da ordem e há muitos dos seus aspectos estruturais e sistemáticos, que acabam por favorecer o autoritarismo, a indiferença e o abuso dentro do confessionário. Dentre os dados que nos chocam, é impressionante saber que muitas vezes o abuso sexual clerical está intimamente ligado ao sacramento da reconciliação, pois este começa com um tom espiritual dentro do confessionário. Então, o confessionário, lugar cuja intenção originária deveria ser anunciar o dom da misericórdia ilimitada de Deus, tornou-se para muitos um lugar onde se experimenta a morte, a destruição da integridade espiritual e onde se é lesado na própria dignidade de ser humano.

Palavras-chave: Crise. Sacramento da Penitência. Ministério ordenado. Clericalismo. Abuso.

\begin{abstract}
This article seeks to approach the crisis of the sacrament of penance internally, that is, it presents that the crisis of this sacrament meets the crisis of the sacrament of the order and there are many of its structural and systematic aspects, which end up favoring authoritarianism, indifference and abuse within the confessional. Among the data that shock us, it is impressive to discover that clerical sexual abuse is often closely linked to the sacrament of reconciliation, as it begins with a spiritual tone within the confessional. So, the confessional, a place whose original intention should be to announce the gift of God's unlimited mercy, has become for many a place where death is experienced, the destruction of spiritual integrity and where one is injured in the very dignity of being human.
\end{abstract}

Keywords: Crisis. Sacrament of Penance. Ordained Ministry. Clericalism. Abuse.

* Doutorando em Teologia Sacramentária (Pontifício Ateneu Santo Anselmo, Roma). Mestre em Teologia Sacramentária (Pontifício Ateneu Santo Anselmo de Roma, Roma, 2015). Bacharel em Teologia (Instituto São Boaventura, Pontifícia Faculdade Seraficum de Roma, Roma, 2012). Licenciado em Filosofia (Universidade Católica de Brasília, Brasília, DF, 2008). Professor ordinário no Instituto São Boaventura, de Brasília.

E-mail: frluisfelipe@gmail.com 


\section{Introdução}

Essa nossa contribuição abordará dois sacramentos, o da penitência e o da ordem, que nos últimos anos veem-se diante de muitas crises. Em geral, é quase óbvio falar dessas crises. A crise da penitência é um fato testemunhado por muitos autores, inclusive, pelo próprio magistério e vivenciado nas nossas comunidades. A crise toca, em particular, o elemento frequência, posto que uns frequentam demais, abusando do sacramento para suas inconscientes perguntas, e outros não mais o frequentam, acreditando ser um sacramento desnecessário para o seu individual caminho de fé. A crise da ordem toca o elemento identidade, espiritualidade, modelo, formação.

Evidentemente, por diversas vezes já se procurou pelas causas, porém nos agarramos mais aos sintomas que às causas. ${ }^{1}$ São muitos, complexos e interligados entre eles. É um fenômeno poliédrico e irredutível que não pode ser simplificado. ${ }^{2}$

Num primeiro momento, focando na crise relacionada ao sacramento da penitência, vemos que a justificativa quanto à não frequência ao sacramento por parte de grande número dos fiéis dá-se pela crise moral, pelo enfraquecimento do sentido religioso da vida, marcando a perda do sentido de pecado, com a falta de confiança na misericórdia de Deus, com a ignorância da função do ministro do sacramento, com o significado do sacramento, com o não saber se confessar e qual a matéria do sacramento. Contudo, o que podemos perceber é que ao tentar solucionar a crise do sacramento da penitência, a resposta toca sempre as causas externas da situação, consequência da presumida secularização do mundo, focando sempre no penitente. Então, nos perguntamos, até quando permaneceremos ancorados nessa perspectiva? Será mesmo o penitente a causa principal da crise do sacramento?

\section{Diagnóstico - sintomas e possíveis causas da crise}

Desfocando a crise do sacramento da penitência na frequência e em alguns outros aspectos, sinalizados acima, queremos direcioná-la

1 Cf. BELLI, M. Sacramenti tra dire e fare. Piccoli paradossi e rompicapi celebrativi. Brescia: Queriniana, 2018. p. 188

2 Cf. BUSCA, G. La riconciliazione: tra crisi, tentativi di riforma e ripensamento. Lo stato attuale della riflessione teologico-pastorale. In: IL SACRAMENTO della penitenza. Milano: Glossa, 2010. p.11. 
para uma leitura interna da situação. Se os sintomas e as causas de uma progressiva e acelerada crise do sacramento da penitência são visíveis, o que dizer dos sintomas e das causas da crise do ministério do sacramento? Por todos os lados se procura um porquê. Diversas são as dimensões que buscam dar uma resposta. Todavia, em primeiro lugar, o que fica muito evidente hoje em dia é que não existe uma boa e ampla disposição eclesial para responder à crise. Talvez, porque não entendemos profundamente a seriedade do problema.

Pode parecer que os exemplos que daremos a seguir sejam por demais caricaturados, negativos e arbitrários; sem dúvidas, merecem um ulterior aprofundamento, mas o que queremos inferir com os exemplos parte da hipótese de uma leitura interna e da observação das generalizações midiáticas. Em particular, nosso objetivo também não é polemizar a questão, embora o nosso título pareça sublinhar essa intenção, mas abordar com maior lucidez e clareza um dos aspectos que deve ser considerado na desejada reforma da Igreja.

Certamente, temos um grande número de bons presbíteros que não fazem parte desse quadro, mas acabam por viver na pele e no quotidiano as consequências dessa leitura, pois acontece que muitas iniciativas, organismos e modelos ligados à Igreja, em vez de deixar transparecer a ação do Espírito Santo, acabam por dar testemunho apenas de uma autorreferencialidade. $^{3}$

Com efeito, a intenção de uma leitura interna da situação tem base na constatação que papa Francisco faz em Amoris Laetitia, que embora distante desses dois particulares sacramentos que estamos tratando, pode servir para a nossa observação: "devemos ser humildes e realistas, para reconhecer que às vezes a nossa maneira de apresentar as convicções cristãs e a forma como tratamos as pessoas ajudaram a provocar aquilo de que hoje nos lamentamos, pelo que nos convém uma salutar reação de autocrítica". ${ }^{4}$

Assim, dentre as atitudes internas relacionadas com o presbítero dentro do exercício do ministério do sacramento da penitência podemos sublinhar: a atitude do indiferente, pela qual não se quer ouvir falar de certos argumentos, fechando o discurso do penitente imediatamente sem o mínimo de respeito com a sua situação; a atitude do indagador,

3 Cf. FRANCISCO. Mensagem às Pontifícias Obras Missionárias, 21 maio 2020.

4 FRANCISCO. Amoris Laetitia, n. 36. 
que ocupa-se em querer saber dos mínimos detalhes; a atitude do surdo, que finge não escutar para não contaminar-se ou para não expor a danos a sua virtude e santidade de vida; a atitude paternalista, o "paizão", de vez em quando, extremamente laxista; a atitude do ignorante e do experiencialista; a atitude do herói-romântico, com seu ideal de cristianismo brilhante, tornando-se o modelo a ser imitado; a atitude do clericalista, com a autossuficiência do mínimo necessário; a atitude daquele que repete sempre "o povo não sabe se confessar, nem sequer sabe dizer a matéria mínima para o sacramento acontecer; o que posso eu fazer?"; a atitude regada de afetuosidade que entende criar um clima de confiança, mas na realidade instaura uma atmosfera erótica; a atitude do terrorista, que procurar aumenta o medo da punição e o sentido da culpa; a atitude do moralista, que com sua rigidez se apresenta como intransigente defensor dos valores inegociáveis; a atitude do hipócrita, que simula virtudes e bons sentimentos para enganar o próximo, fazendo o penitente ver nele uma pessoa íntegra e integrada, uma amizade puríssima, de amor, de fé religiosa; a atitude do psicólogo, consulente, terapeuta, coaching. ${ }^{5}$

É evidente que temos muitas outras, uma mais paradoxal e grave que a outra. Aprende-se, insiste-se e sabe-se muito de retórica clerical, canônica, litúrgica, sacramental e moral, mas pouco ou muito pouco de autoridade ritual, ministerial e carismática, distorcendo o princípio básico do evangelho e deixando comprometida a própria estrutura de Igreja. E, como sabemos, corremos sempre risco quando vemos uma aliança entre formalismos oficiais e sentimentalismos individuais. Bem disse o papa Francisco:

jamais se pode pensar em servir a missão da Igreja cultivando a arrogância, seja como indivíduos seja através dos organismos, com a altivez de quem distorce até o dom dos sacramentos e as palavras mais autênticas da fé cristã como se fossem um espólio que ganhamos. ${ }^{6}$

A partir de tudo isso, como podemos observar, dizer que o sacramento da ordem ou o ministério do sacramento da penitência está passando por uma crise é quase banal. É uma situação um tanto quanto óbvia e evidente, drástica e dramática, que merece ser adequadamen-

5 Algumas dessas atitudes internas relacionadas ao ministério do sacramento da penitência podem ser encontradas no estudo de TARGONSKI, F. II sacramento della penitenza in prospettiva antropologica. In: Miscellanea Francescana 115 (2015), p. 462-464.

6 FRANCISCO. Mensagem às Pontifícias Obras Missionárias, 21 maio 2020. 
te considerada. São crises que se manifestam nas suas mais diversas dimensões. ${ }^{7}$

Diante disso, temos um outro dado bastante paradoxal. Temos um tempo de formação cada vez mais longo, com exigências e critérios formativos sempre mais precisos, mas que parecem nunca ser o suficiente. Todavia, é provável que esse longo tempo que estamos passando continue a não levar suficientemente a sério uma necessária e urgente mudança, ou uma valorização das propostas dos últimos anos, pois é possível que o nosso medo considere que tudo seja como antes. É constante em nós a tendência a se fechar nos métodos antigos e de tomar uma atitude de defesa diante da nova cultura, sintetizando todos os problemas como secularização e perdas.

Também paradoxalmente, não somente o imaginário simbólico caricaturado por uma opção midiática, pelo excesso de zelo jurídico-moral, inclusive por vezes carente do sentido evangélico, adotando um evangelho paralelo ao evangelho de Cristo, mas também por fatos extremamente desconfortáveis dentro do confessionário, interpretaram e consolidaram essas formas ministeriais e marcaram esse espaço salvífico como lugar da indiferença, do autoritarismo e do abuso.

É um assunto por demais doloroso que interpela-nos a buscar uma nova resposta, uma ação e uma atitude. Tais problemas não são novos na história da humanidade e não é uma realidade nova na história da Igreja. De maneira feliz, a humanidade e a Igreja estão conseguindo avançar, mesmo que lentamente, com algumas novas e eficazes possibilidades para deter o problema.

Olhando um pouco a questão do abuso clerical, lamentavelmente, como constata o cardeal Schönborn em uma de suas entrevistas, "é impressionante descobrir como o abuso sexual clerical está intimamente ligado ao sacramento da reconciliação e descobrir que ele muitas vezes começa no confessionário"8. Bem verdade que esse dado apresenta-se por demais generalizado, podendo ser somente uma leitura isolada da

7 Cf. BELLI, 2018, p. 222.

8 Cf. SCHÖNBORN, C. A chocante realidade dos abusos sexuais clericais. Disponível em: http://www.ihu.unisinos.br/78-noticias/594750-schoenborn-explica-a-chocante-realidade-dos-abusos-sexuais-clericais. Acesso em: 9 set. 2020; SCHONBORN, C. Um espiral do silêncio está no cerne dos abusos sexuais clericais em curso. Disponível em: http://www.ihu.unisinos.br/590694-cardeal-schoenborn-uma-espiral-do-silencio-esta-no-cerne-dos-abusos-sexuais-clericais-em-curso. Acesso em: 9 set. 2020. 
situação, mas é um dado relevante, que não pode ser justificado pelo número de ocorrências, merecendo uma ulterior pesquisa que evidencie este vínculo. $\mathrm{O}$ dado geral e chocante que queremos sublinhar é que quase todas as vulneráveis vítimas são pessoas muito próximas à Igreja. ${ }^{9}$ Dessa forma, o confessionário, lugar cuja intenção originária é anunciar o dom da misericórdia ilimitada de Deus, tornou-se para muitos um lugar onde se experimenta a morte, a destruição da integridade espiritual, onde se é lesado na própria dignidade de ser humano. Isso é bastante alarmante e deprimente. Não podemos mais negar a natureza institucional dessa crise. ${ }^{10}$

Como pode isso acontecer? Além de deixar-nos sem palavras e impotentes, isso questiona a nossa humanidade. Num momento de maior fragilidade quando o cristão-batizado-pecador aproveita para se reconciliar com Deus e com a Igreja, o agressor aproveita para fazer as suas vítimas. Muitos usam a sua posição na Igreja ou a sua autoridade espiritual para satisfazer suas próprias necessidades ou os seus desejos autocentrados e perversos. ${ }^{11}$ Por isso, o abuso clerical sexual ou moral constitui sempre um abuso de poder, pois a estrutura clerical da Igreja facilita o autoritarismo. A partir daí, para que a Igreja encontre uma nova credibilidade deverá ser sincera consigo mesma e coerente na sua salutar capacidade autocrítica, porque a nossa atual situação não é por nada confortável.

Uma outra pergunta fundamental poderia ser: qual o núcleo gerador dessas situações por demais dramáticas? Numa rápida resposta poderíamos dizer, com Ghislain Lafont, que é a sacerdotalização do ministério, resultado de uma estruturação sistemática, ligada à uma forma de Igreja

9 Cf. ZOLLNER, H. Onde dizem 'aqui não há abusos', significa somente que ali não se fala sobre isso. Há em todas as partes. Disponível em: http://www.ihu.unisinos.br/78-noticias/586636-onde-dizem-aqui-nao-ha-abusos-significa-que-ali-nao-se-fala-ha-em-todas-as-partes. Acesso em: 9 set. 2020. Para um ulterior aprofundamento indicamos: PORTILLO, D. Igreja ainda não entendeu a seriedade do problema dos abusos sexuais. Disponivel em: http://www.ihu.unisinos.br/78-noticias/594316-igreja-ainda-nao-entendeu-a-seriedade-do-problema-dos-abusos-sexuais. Acesso em: 9 set. 2020; SCHICKENDANTZ, C. Fracaso institucional de un modelo teológico-cultural de Iglesia. Factores sistémicos en la crisis de los abusos. Teología y Vida, n. 60 (2019/1), p. 9-40.

10 Cf. LEGRAND, H. Clericalismo e abuso sexual: por que tamanha inércia? Disponível em: http://www.ihu.unisinos.br/600353-clericalismo-e-abuso-sexual-por-que-tamanha-inercia. Acesso em: 9 set. 2020.

11 Cf. MICKENS, R. Os católicos ainda não entenderam: os abusos sexuais não têm a ver com sexo. Disponível em: http://www.ihu.unisinos.br/78-noticias/596635-os-catolicos-ainda-nao-entenderam-os-abusos-sexuais-nao-tem-a-ver-com-sexo. Acesso em: 9 set. 2020. 
transmitida pela reforma gregoriana, ${ }^{12}$ que, sacralizando a exterioridade, exigiu um temor reverente e autorreferencial, uma perigosa concepção do poder (sacra potestas), ${ }^{13}$ lógica essa que continua a produzir seja causadores como vítimas. ${ }^{14} \mathrm{E}$ mais, sendo confirmada pela reforma tridentina que operou definições, determinando e delimitando tudo.

É difícil negar que, no curso da história, os efeitos da ordenação foram sobrestimados, descaracterizando todos os ministérios sempre mais do seu aporte carismático e mudando o modo de entender a cura animarum. O sacerdote é descrito como "outro Cristo", "mediador entre Deus e os homens", "sacerdote para sempre", "superior aos anjos". Algumas espiritualidades chegaram a descrevê-lo como fonte fecunda e inexaurível da graça. O Vaticano II certamente reequilibrou esta espiritualidade sacerdotal, mas continuou tomando para si, expressões técnicas suscetíveis a ambiguidades, como in persona Christi..$^{15} \mathrm{Na}$ realidade essa espécie de idealização abstrata é a origem e não a solução do problema. ${ }^{16}$

Tais detalhes são quase que suficientes para demostrar porque o Papa Francisco se inquieta em ver "o clericalismo subavaliar a graça batismal". ${ }^{17} \mathrm{E}$, desse modo, entender que a graça do batismo é igualmente menosprezada pelos ministros ordenados influenciados por esta pseudoespiritualidade sacerdotal, uma vez que o batismo deve ser o único fundamento da santidade dos mesmos.

De fato, o clericalismo nasce de uma visão elitista e exclusivista da vocação, que interpreta o ministério recebido como poder a ser exercido ${ }^{18}$. A vocação é comumente compreendida como um chamado, interior e

12 Cf. LAFONT, G. Immaginare la Chiesa cattolica. Linee e approfondimenti per un nuovo dire e un nuovo fare della comunità cristiana. Cinisello Balsamo: San Paolo, 1998. p. 39-65; LAFONT, G. Storia teologica della chiesa. Itinerario e forme della teologia. Cinisello Balsamo: San Paolo, 1997. p. 87-115, p. 205-228.

13 Cf. BATTOCCHIO, R. Note storiche e teologiche sul dibattito attorno alla distinzione fra potestas ordinis e potestas iurisdictionis. In: AUTORITÀ e forme di potere nella chiesa. Milano: Glossa, 2019. p. 125-154.

14 Cf. BOGNER, D. Questa chiesa uccide. Disponível em: http://www.settimananews.it/ chiesa/questa-chiesa-uccide. Acesso em: 9 set. 2020.

15 Cf. LEGRAND. Clericalismo e abuso sexual: por que tamanha inércia? Acesso em: 9 set. 2020.

16 Cf. MICHAELDAVIDE, F. Preti senza battesimo: Una provocazione, non un giudizio. Cinisello Balsamo: San Paolo, 2018. p. 29.

17 FRANCISCO. Carta ao povo de Deus, 20 ago. 2018.

18 Cf. LEBRA, A. Clericalismo. Disponível em: http://www.settimananews.it/chiesa/clericalismo-2/. Acesso em: 30 set. 2020. 
misterioso, que provém diretamente do próprio Jesus, uma escolha de Deus anterior àquela da Igreja. Esta vocação força ainda mais o respeito da parte dos fiéis enquanto implica renúncias, a constituir uma família, por exemplo, e a promessa de um devotamento total e filial. Não é sem razão que qualificamos uma vida de doação aos outros como um verdadeiro sacerdócio! Tal concepção da vocação, inscrita na linguagem usual ('tornar-se padre'), é contrária à tradição recordada por São Pio X, ainda em 1912: "A vocação não consiste, de modo algum, num convite do Espírito Santo para abraçar o sacerdócio, mas em um apelo que a Igreja faz a um cristão, no qual ela discerne as aptidões necessárias". Contudo, vinte anos mais tarde, Pio XI, exigindo que os ordenandos jurassem sobre os santos evangelhos: "Experimento e sinto que Deus me chama realmente", consagrou este subjetivismo moderno ruinoso, contra um equilíbrio entre a eleição pela Igreja e a eleição por Deus. ${ }^{19}$

Sendo assim, é preciso delinear uma mudança paradigmática. Não é tarefa fácil nem de curto prazo. É preciso passar da indignação à conversão. De fato, não basta indignar-se, é necessário deixar-se interrogar pelas adversidades e pelas vítimas. O desafio é aquele de entrar em um intenso processo de conversão do coração e da mente. Essa conversão não pode ser simplesmente uma reação às denúncias que vêm de fora, mas fruto de desejo autêntico de uma vida mais evangélica. ${ }^{20}$

Em um certo momento, após as novidades e o frescor do Concilio Vaticano II, acreditou-se que bastavam formações e exortações. Contudo, nunca foram suficientes, justamente porque essas comportam questões ascético-morais, com espiritualidades adocicadas, marcadas por heroísmos individuais e devocionais. Por exemplo, frequentemente, imaginava-se o sacerdote como mártir do confessionário. Mas, essa imaginação e simbolização consiste numa perigosa dissociação. É impensável que hoje um padre, sobretudo, muito jovem, passe horas dentro de um confessionário sem um mínimo de supervisão; isso não afetaria minimamente o efeito da graça de Deus, mas aumentaria estatisticamente o número de padres, emocionalmente, enfraquecidos e instáveis. ${ }^{21}$ Além do mais, propor hoje como modelo de padre o Cura D'Ars, sem tirar a

19 Cf. LEGRAND. Clericalismo e abuso sexual: por que tamanha inércia? Acesso em: 9 set. 2020.

20 Cf. MICHAELDAVIDE, 2018, p. 14-16.

21 Cf. PEREIRA, W. Sofrimento psíquico dos presbiteros: Dor institucional. Petrópolis: Vozes, 2012. 
grandeza do santo, gera uma série de problemas na forma como esta figura assumiu a sua prática no tempo, no espaço, na cultura e no contexto da sua história. Assim, o ministério sacerdotal está dolorosamente vivendo na pele de tantos bons padres uma questão que todavia é transversal a muitos aspectos da forma da Igreja, somos (e somos chamados a ser) contemporâneos aos nossos contemporâneos, mas em forma que não prevê a nossa contemporaneidade ${ }^{22}$.

Dessa forma, não podemos pensar que a solução nasça de uma dinâmica exortativa e nem mesmo de elucubrações racionais e teológicas ou de exemplos técnicos e funcionais. A solução pode nascer sim de uma possível releitura da questão sacramental e do múnus ministerial, reconduzida por uma certa prática de vida não gerenciada pela superficialidade dos dias. Outras vezes, pensa-se que a solução localiza-se na assistência e na prevenção, certamente é indispensável, mas não é tudo. Tais respostas são suficientes para uma Igreja que deseja manter seu fausto ideológico, mas largamente inadequadas para uma Igreja que deseja viver como comunidade de fé.

No fundo de tudo isso, parece que temos também uma teologia ministerial defeituosa, ${ }^{23}$ capaz de nutrir estruturas de pecado. ${ }^{24}$ Temos sim uma crise clerical e ministerial, mas também temos o fracasso de um modelo institucional e canônico. ${ }^{25}$ Apresentamo-nos sempre mais

22 Cf. MORRA, S. Dio non si stanca: La misericordia come forma ecclesiale. Bologna: Dehoniane, 2015. p. 25.

Cf. BORGMAN, E. Aspectos teológicos en la crisis de los abusos sexuales. In: Concilium, n. 344 (2012/1), p. 143-150.

24 Cf. MORRA, 2015, p. 24.

25 "Per favorire una Chiesa capace di un'arte dell'accompagnamento occorre uscire da una lettura ecclesiologica della Chiesa che, in alcuni giuristi autorevoli, è rimasta, sostanzialmente, quella del Vaticano I. Ed è proprio la condizione di separatezza del diritto rispetto alla teologia - favorita dalla codificazione del 1917 - ad aver accentuato oggi, in modo forse sorprendente, una funzione retrograda e chiusa del diritto canonico rispetto alle logiche nuove. Se la teologia lascia il diritto scivolare in una ecclesiologia ottocentesca, non riuscirà a creare le condizioni per una vera riforma [...] Ciò significa che una svolta pastorale, per essere tale, deve modificare la legge canonica e alimentare un approccio diverso alle questioni in gioco. Questo è un compito tutt'altro che semplice [...] Perché il teologo possa additare una riforma che assuma forme istituzionali adeguate, senza fuggire nelle astrazioni o nelle istanze generiche, e perché il canonista non diventi il difensore dello status quo e non scivoli, progressivamente indietro, dal Vaticano II al Vaticano I e da questo alle magnifiche sorti, e regressive, del tridentino. La teologia e il diritto debbono servire l'ospedale da campo. Solo collaborando in modo nuovo possono aiutare la Chiesa a annunciare il Vangelo e a realizzare la pace della comunione". GRILLO, A. Per un confronto aperto ed efficace tra teologi e canonisti sul matrimonio. Disponível em: http://www.cittadellaeditrice.com/munera/ 
fragmentados. Por isso, somos convictos que se trata de uma asserção de peso teológico relevante e de uma declaração programática sobre o plano eclesiológico ${ }^{26}$ e sacramental-ministerial para os próximos anos. Certamente, isso não é um trabalho que pode ser limitado às poucas linhas dessa reflexão.

Como se vê pelo que acabamos de considerar, não podemos permitir que uma esclerose institucional impeça à Igreja de responder aos novos desafios. Uma nova forma de Igreja inspira novas dinâmicas de serviço e de autoridade, sem escorregar numa fácil retórica. É preciso investir plenamente e generosamente nesse processo de discernimento, purificação e reforma, implicando em uma conversão pastoral, ministerial e missionária. ${ }^{27}$

\section{Prognóstico da (des) ordem}

Nessa dinâmica de serviço e autoridade a questão dos ministérios deve ser revisitada. Aliás, já não é novidade que os ministérios na Igreja pedem para ser revistos e reestruturados. Como dissemos, da mesma forma como o sacramento da penitência é por demais óbvia a crise do ministério ordenado. Muito já foi refletido sobre a questão da identidade, da formação e da questão vocacional. Temos um descolamento muito forte entre ideal e real, onde o idealismo que resulta ser heterogêneo em respeito ao realismo, gera frustração e abuso de poder ${ }^{28}$ inclusive, marcado por uma certa nostalgia do passado, caracterizado por usos e costumes que sinalizam a frágil identidade e tentam esconder o problema.

Estamos em mudança de época! Não podemos deixar as coisas como estão. ${ }^{29}$ Está em jogo nada menos do que a eficácia do agir pastoral e sacramental ${ }^{30}$, que se mede na capacidade de escutar o Espírito e de escolher como converter a sua forma e os seus gestos à ação daquele que torna presente Jesus hoje. Além do mais, isso então não é somente uma

per-un-confronto-aperto-ed-efficace-tra-teologi-e-canonisti-sul-matrimonio/. Acesso em: 9 set. 2020.

Cf. MORRA, S. La misericordia, (ri-)forma della chiesa. Una prospettiva strutturale.

In: Concilium, n. 53 (2017/4), p. 57.

27 Cf. FRANCISCO. Evangelii gaudium, n. 30.

28 Cf. BELLI, 2018, p. 207.

29 Cf. FRANCISCO. Evangelii gaudium, n. 25.

30 Cf. LIBANIO, J. A identidade e a espiritualidade do presbítero no processo de mudança de época. In: Perspectiva Teológica, n. 121 (2011), p. 353-388. 
questão de fidelidade da Igreja ao Evangelho, mas também expressão da sua preocupação messiânica pelo outro e pela sua recepção do próprio evangelho. ${ }^{31}$

Para mudar a imagem da Igreja em uma nova forma, ${ }^{32}$ temos que mudar alguns elementos que estão imbricados numa pesada e ameaçadora dimensão institucional, dentre tantas coisas, uma dessas é o ministério do sacramento da penitência na sua inerência substancial e canônica com o sacramento da ordem. Talvez, essa inerente unidade tem dado provas de que este espaço tem sido transformado em espaço de indiferença, autoritarismo e do abuso de poder. E não só, em manifestação de um automatismo sacramental e de um funcionalismo ministerial.

Indica-se assim que é absolutamente necessário e urgente que a Igreja ou a teologia reencontre uma forma que dê maior significado a este importante serviço para os homens, busque remediar esse ministério para o futuro, por demais arraigado na sua improvisação canônica da faculdade, e comece a nutrir um novo imaginário simbólico que possa interpretar de modo mais saudável o sacramento da penitência.

Fica evidente, que tudo isso não seria só uma questão logística ou uma espécie de solução técnica a um grave problema, para manter o status quo da vida da Igreja, mas uma questão de encontrar um modo pelo qual o ministério recupere também uma qualidade espiritual e sacramental que não seja reduzida a uma faculdade improvisada. Formar para essa dinâmica não quer dizer que é preciso dotar o ministro de todas as qualidades humanas, éticas e técnicas, mas de uma maturidade suficiente que o ajude a desenvolver o próprio serviço da melhor maneira possível. A resposta para os problemas não deve partir da pergunta "quem é o bom ministro confessor?", mas deve ir além, pois seja a pergunta como a sua resposta parecem por demais superficiais. Somente um maduro exercício de responsabilidade, que não é possível alcançar dentro da estrutura "infantilizada" de uma casa de formação, pode preservar a instituição dos abusos e da perversão. Obviamente é necessário, para que as várias estruturas sejam exercitadas de maneira saudável e profícua, individuar sujeitos, procedimentos, lugares e tempos. Dessa forma, para avaliar a responsabilidade de um ministro devem ser considerados diversos elementos, sejam pessoais que relacionais e contingentes. Pode-se dizer que

31 Cf. THEOBALD, C. II coraggio di anticipare il futuro della Chiesa. In: Concilium, n. 54 (2018/4), p. 26.

32 Cf. MORRA, 2017, p. 56-66. 
o sentido de responsabilidade baseia-se em aspectos antropológicos e éticos, em particular, em um projeto de vida, de pensamento e de ação. ${ }^{33}$

Sem dúvidas, o pontificado de Francisco, com a sua clássica insistência no sacramento da penitência, está convocando indiretamente à teologia a oferecer clarificações, a partir da construção dessa nova forma eclesial, sobre o ministério do confessor, para não favorecer os típicos mecanismos de improvisação de tal ministério. ${ }^{34}$ É com constante insistência que o mesmo repete: "não invalidemos estes momentos com comportamentos que possam contradizer a experiência da misericórdia que se procura". ${ }^{35}$ Vemos que nessa preocupação existe um sopro autenticamente profético que pode nos ajudar a construir novidades que sejam a causa das nossas futuras esperanças.

Sendo assim, o contexto eclesial de que participamos hoje pede não somente para ultrapassar algumas categorias eclesiológicas tradicionais, sobretudo, as que insistem sobre a essência a-histórica da Igreja, mas também abertura a uma visão de historicidade qualificante do ministério ou de um amadurecimento que respeite o tempo e a experiência do ministro ordenado. Não basta argumentar. Deve-se entender a história com os critérios do tempo ${ }^{36}$ pois "o tempo é superior ao espaço". ${ }^{37}$ Esse princípio convida a Igreja a assumir a tensão entre plenitude e limite. ${ }^{38}$ É um princípio que permite dar tempo ao tempo, "sem a obsessão pelos resultados imediatos". ${ }^{39}$ Esta é uma abordagem que pode guiar o discernimento, o acompanhamento e a ação pastoral em direção à ação do Espírito $\operatorname{Santo}^{40}$ e ao testemunho pastoral que constrói pessoas e reconstrói instituições. Tais atitudes pressupõem um coração pacificado por Cristo, liberto daquela agressividade que brota dum ego demasiado grande $\mathrm{e}^{41} \mathrm{e}$ de um sentido equivocado do serviço ministerial. Sendo assim, a primeira reforma deve ser a das atitudes. Os ministros do Evangelho devem ser

33 Cf. D'AMBROSIO, R. Mutazione del potere nella società e nella Chiesa. In: ASSOCIAZIONE TEOLOGICA ITALIANA. Autorità e forme di potere nella chiesa. Milano: Glossa, 2019. p. 12-13.

Cf. FRANCISCO. Misericordiae vultus, n. 17.

35 FRANCISCO. Misericordia et misera, n. 11.

36 Cf. BOFF, L. Igreja, carisma e poder. São Paulo: Ática, 1994. p. 106.

37 FRANCISCO. Evangelii gaudium, n. 222.

38 Cf. FRANCISCO. Evangelii gaudium, n. 222.

39 FRANCISCO. Evangelii gaudium, n. 223.

40 Cf. FRANCISCO. Gaudete et exsultate, n. 41.

41 Cf. FRANCISCO. Gaudete et exsultate, n. 121. 
pessoas capazes de aquecer o coração das pessoas. ${ }^{42}$ Isso requer fidelidade concreta às experiências humanas e aos processos da história. ${ }^{43}$

O serviço que o sacerdote presta como ministro, por parte de Deus, para perdoar os pecados é muito delicado e exige que o seu coração esteja em paz, que o presbitero tenha o coração em paz; que não maltrate os fiéis, mas que seja manso, benévolo e misericordioso; que saiba semear esperança nos corações e sobretudo que esteja consciente de que o irmão ou a irmã que se aproxima do sacramento da reconciliação procura o perdão, e fá-lo como as numerosas pessoas que se aproximavam de Jesus para serem curadas. O sacerdote que não tiver esta disposição de espirito é melhor que, enquanto não se corrigir, não administre este sacramento. Os fiéis penitentes têm o direito, todos os fiéis têm o direito de encontrar nos sacerdotes servidores do perdão de Deus. ${ }^{44}$

Então, para sermos mais coerentes com o nosso tempo, com o que reconquistamos com o Concílio Vaticano II e estamos perdendo, e a mudança de época que vivemos, não podemos mais presumir o ministério com critérios objetivos, como uma chamada do alto, como um poder a ser exercitado. ${ }^{45}$ Tais formas de abordar a ministerialidade estão dando provas de falência e esgotamento. A hora é agora! Não podemos mais continuar fundando a mediação sacerdotal sobre certezas abstratas e categorias jurídicas. É importante entender que

a instituição não é um em si, mas uma função em favor da comunidade de fé. Em decorrência disso, ela é sempre derivada, deve caminhar no mesmo passo das transformações históricas pelas quais passa a comunidade, deve enfrentar as rupturas e encontrar respostas institucionais adequadas. ${ }^{46}$

Portanto, é preciso despotencializar o ministério dessa carga imposta pelo sistema convencional para, libertando-se desses significados, torná-lo de novo significante e significativo neste nosso tempo.

42 Cf. SPADARO, A. Intervista a papa Francesco. In: La Civiltà Cattolica, n. 3918 (2013), 462.

43 Cf. FRANCISCO. Evangelii gaudium, n. 225.

44 FRANCISCO. Audiência geral, 20 nov. 2013.

45 FRANCISCO. Discurso à I Congregação geral da XV Assembleia geral do Sínodo dos bispos sobre "os jovens, a fé e o discernimento vocacional", 3 out. 2018.

46

BOFF, 1994, p. 93. 
Em primeiro lugar, trata-se de restaurar na concepção e na prática da Igreja o primado do sacramento e aquele do Espírito Santo e, consequentemente, diminuir o impacto do direito, que corre o risco de esconder elementos importantes da fé e da vida cristã. ${ }^{47}$ Quando Papa Francisco insiste que "dizer não aos abusos, é dizer não, em modo categórico, a qualquer forma de clericalismo" ${ }^{48}$ é claramente consciente que o tipo de autoridade e de poder reconhecido ao clero na Igreja deve ser reformado. ${ }^{49}$ Ainda, afirma G. Lafont: "naquilo que concerne a transformação estrutural da Igreja, a mudança mais notável me parece ser aquela que diz respeito à autoridade. Digo autoridade porque considero seja esta a palavra que deve substituir aquele, um tempo corrente, de poder". ${ }^{50}$ Isso implica uma atitude de despojamento, de pobreza interior, de conversão permanente, onde precisamos largar conquistas gloriosas do passado que adoeceram, para servir à comunidade e ao Senhor atuante nela, para sermos serviço salvífico para o mundo. ${ }^{51}$

Enfim, além de algumas possíveis soluções lançadas acima de forma generalizada, merecendo um estudo bem mais específico e aprofundado, a desordem da Ordem no sacramento da penitência pode ser resolvida com uma articulação fundamental entre três categorias, a saber, a misericórdia, a autoridade e o carisma.

\section{Possibilidades e prospectivas}

A misericórdia é o ponto de partida, o critério originário que pode libertar a ação ministerial dessas cristalizações que desfiguram e arrastam com força para um caus. ${ }^{52}$ Por essa razão, a misericórdia é o princípio hermenêutico do pontificado de Francisco e um tema transversal ao seu ensinamento. Não é somente um lema, um carisma, uma força existencial,

$47 \quad$ Cf. LAFONT, 1998, p. 65.

48 FRANCISCO. Carta ao povo de Deus, 20 ago. 2018.

49 Cf. LEGRAND. Perché non abbiamo agito?, 4.

50 LAFONT, G. La Chiesa: il travaglio delle riforme. Immaginare la Chiesa cattolica. Cinisello Balsamo: San Paolo, 2012. p. 169-170.

51 Cf. BOFF, 1994, p. 93.

52 Cf. FERRETTI, G. Il criterio misericordia. Sfide per la teologia e la prassi della Chiesa. Brescia: Queriniana, 2017. 
uma doutrina viva, um modo de governo. ${ }^{53}$ É o primado do amor a lógica que deve acompanhar, discernir e integrar. ${ }^{54}$

É necessário recomeçar sempre por este ponto firme: Deus tratou-me com misericórdia. Eis a chave para nos tornarmos colaboradores de Deus. Experimentamos a misericórdia e somos transformados em ministros da misericórdia. ${ }^{55}$

Isso bem entendeu o Papa Francisco ao sintetizar a misericórdia como ponto saliente do seu pontificado. "É a misericórdia que livra o ministro de ser um padre juiz-funcionário que, à força de tanto julgar casos, perde a sensibilidade pelo rosto das pessoas". ${ }^{56}$

Entretanto, temos a necessidade de sair de uma visão da misericórdia confinada no âmbito interior e individual, ${ }^{57}$ como lugar de um exercício ascético pessoal, viciada por uma visão sentimental e intimista. Assim, para a estrutura encarnada da Igreja, a misericórdia diz respeito à dimensão pública, visível e histórica da comunidade dos crentes. ${ }^{58}$ Por isso, refletir sobre essa categoria, é absolutamente necessário, nunca suficiente e muito menos cansativo. ${ }^{59}$ A nova inteligência do tempo, do espaço, da criação, do humano, de tudo aquilo que está em movimento, sendo construído ou destruído, da Igreja e da sociedade, está abrindo perspectivas críticas sobre as formas da mediação desse amor. Assim, a

53 Cf. SCANONNE, J. La Ética Social del Papa Francisco. El Evangelio de la misericordia según el espíritu de discernimento. Teología, n. 126 (2018), 146.

Cf. GALLI, C. "Revolución de la ternura y reforma de la Iglesia". Medellín, n. 170 (2018), 75.

FRANCISCO. Discurso aos missionários da misericordia, 10 abr. 2018.

Cf. BIANCU, S. II massimo necessario. L'etica alla prova dell'amore. Milano: Mimesis, 2020. p. $112-118$.

É bom aqui recordar que para anunciar a misericórdia e o perdão de Deus não podemos partir estruturalmente do sacramento da penitência. Isso não significa diminuir a importância do sacramento, mas quer significar que temos que ficar atentos para não darmos a ele um lugar de exagerada importância. Banalizamos os sacramentos não somente quando os transcuramos, mas também quando se exige a recorrência em modo sobreabundante ou impróprio. Para quem deve ter cura de uma paróquia essa advertência é fundamental, pois a penitência é lugar do anúncio e da eficácia da misericórdia em um modo que resulta secundário; isto deve sempre reenviar aos lugares primários da experiência do pecado e do perdão, ou seja, o batismo e a eucaristia. Cf. GRILLO, A. Grazia visibile, grazia vivibile. Teologia del sacramenti in genere ritus. Padova: Messaggero, 2008. p. 211, 217-219. 
benevolência (amor benevolentiae) deve provocar e implicar um novo olhar sobre as pessoas. ${ }^{60}$

A misericórdia é em tudo o contrário da indiferença, do autoritarismo e do abuso; exige escuta, permite, então, guiar os passos do pecador reconciliado à sua dignidade cristã e integridade da sua humanidade. Deus liberta do medo, da angústia, da vergonha, da violência.

O perdão realmente é uma forma de libertação para restaurar a alegria e o sentido da vida. Ao grito do pobre que invoca ajuda, corresponde o grito do Senhor que promete a libertação dos prisioneiros e aos que estão nas trevas, diz: "Vem para fora". Um convite para sair da condição de pecado e retomar a de filhos de Deus. Em suma, a misericórdia libertando restaura a dignidade. ${ }^{61}$

A misericórdia deve ser, então, a objetividade mais harmoniosa que precisamos para que a ideia esteja a serviço da captação, da compreensão e da condução da realidade. Muitas vezes o uso distorcido de categorias clássicas, antes de garantir uma inteligência correta e plausível, bloqueou de modo autorreferencial a possibilidade de tocar o real. ${ }^{62}$

Dessa forma, a credibilidade da Igreja, a fim de alcançar uma meta mais alta e significativa, deve passar por essa estrada, senão será infecunda e estéril, pois a primeira verdade da Igreja é o amor de Cristo. ${ }^{63}$ Sem a misericórdia tudo aquilo que fazemos corre o risco de desmoronar na mesquinhez burocrática ou na ideologia, que por sua natureza quer domesticar o mistério. ${ }^{64}$ A partir disso, como já afirmamos, muitas formas que foram pensadas, estruturadas e vivenciadas, que eram boas em um tempo, não funcionam mais e, com isso, sem destruí-las ou negá-las, é preciso transformá-las profundamente. ${ }^{65} \mathrm{E}$ mais, é importante entender que as reformas que urgentemente precisamos não são necessárias somente para enfrentar a atual e permanente crise, mas condicionam também a renovação pastoral exigida pelas novas condições culturais e humanas.

$60 \quad$ Cf. LAFONT, 2012, p. 137.

61 FRANCISCO. Discurso aos missionários da misericórdia, 10 abr. 2018.

62 Cf. FRANCISCO. Evangelli Gaudium, n. 232.

63 Cf. FRANCISCO. Misericordiae Vultus, n. 11-12.

64

Cf. FRANCISCO. Carta por ocasião do centenário da Faculdade de Teologia da Pontifícia Universidade Católica Argentina, 3 mar. 2015.

65 Cf. LAFONT, G. Piccolo saggio sul tempo di papa Francesco. Bologna: Dehoniane, 2017. p. 15. 
Por conseguinte, o segundo elemento que deve contribuir para a nova articulação do ministério é a autoridade, não só infundida do alto, mas adquirida. É preciso identificar bem a questão da autoridade, precisamente pelo fato de que o nosso modo de ler a autoridade se tornou por demais simplificado nos últimos dois séculos a ponto de hoje custarmos tanto a redescobri-la em seu sentido bíblico-teológico. Poderíamos dizer que o "senso comum" identifica por autoridade aquela força, aquele poder, aquela palavra que tem a característica de imposição. No entanto, o sentido original do termo autoridade pode dar novo valor a essa perspectiva, que por sinal é muito pobre. A autoridade é, mais originalmente, capacidade e poder de fazer crescer. Ter autoridade é um serviço para o amadurecimento e o crescimento do outro. ${ }^{66}$

Nessa perspectiva, aquele que possuiu autoridade é capaz de inaugurar no outro uma nova percepção que antes não era possível, dando a ele permissão ou potencialização, e não o contrário. Por sua vez, a autoridade se reveste de duas características. De um lado, suscita novas respostas. Nos faz falar. Dá lugar a uma outra coisa. É uma questão de verdade. ${ }^{67}$ Permite-nos dizer ou fazer o que não seríamos sem essa verdade. Por outro lado, cria um espaço. Torna possível as diferenças. Ele ouve uma palavra e cria outra. ${ }^{68}$ "Torna possível uma nova práxis". ${ }^{69}$ A autoridade, nesse sentido, é incompatível com a persuasão e a coerção, princípio do abuso de poder, sobretudo, porque esses elementos dominam de modo definitivo o conceito e a lógica da liberdade..$^{70}$

Com isso, aquele que possuiu uma certa autoridade tem uma capacidade altamente performativa. Dessa forma, a autoridade é espiritual no seu princípio e no seu exercício. ${ }^{71} \mathrm{Tal}$ dinamicidade é prevista para um homem de autoridade; por exemplo, o próprio Jesus quando na constatação dos seus milagres diz: "tua fé te salvou, vai em paz" $(\operatorname{Lc} 7,50) .{ }^{72}$

66 Cf. GRILLO, A. Um dissídio sobre autoridade, entre Agamben e Neri: direitos e deveres em conflito. Disponível em: http://www.ihu.unisinos.br/78-noticias/599278-um-dissidio-sobre-a-autoridade-entre-agamben-e-neri-direitos-e-deveres-em-conflito. Acesso em: 9 set. 2020.

Cf. CERTEAU, M. Autorités chrétiennes. In: Études, n. 332 (1970), p. 374-375. 
Consequentemente, diante da nossa geração, sempre à procura de novas autoridades, é preciso considerar qual a natureza, o princípio e a forma dessa autoridade. Para fazer crescer o outro, a misericórdia/ compaixão deve ser "o núcleo e a natureza da autoridade", ${ }^{73}$ ou seja, um homem de Deus, um ministro na sociedade contemporânea, só poderá ser credível, no seu próprio espaço e, até mesmo, além dele, por exemplo, devolvendo ou dando autoridade à sua instituição, se tornar visível e vivível a capacidade de compaixão que Deus tem pelo homem, gerando nele vida ao invés de morte, fazendo com que o mesmo tenha novas percepções da sua atual condição e daquela que pode ser.

Nesse sentido, a função de ministro na sociedade contemporânea deve ser aquela de tirar fora o melhor do homem e de fazê-lo proceder em direção de uma comunidade mais humana ${ }^{74}$ e de uma vida mais integrada, sabendo dar espaço ao primado da consciência. Então, a autoridade é tal na medida em que é percebida como mediação confiável e desinteressada, como símbolo e testemunho, de um sentido fecundo ${ }^{75}$ e performativo de uma verdade. ${ }^{76}$ Por isso, a autoridade também não é simplesmente a característica de algumas pessoas, mas é o resultado de uma particular relação simbólica com o mundo, com o tempo e com as experiências que o rodeiam.

Por fim, o último elemento dessa articulação é o carisma. A ligação geradora entre misericórdia e autoridade nos conduz à necessidade de uma intuição mais carismática no exercício ministerial. ${ }^{77}$ Uma autoridade qualificada e evangélica deriva do próprio carisma do ministério.

73 H. NOUWEN. /I guaritore ferito. II ministero nella società contemporanea. 11. ed. Brescia: Queriniana, 2017. p. 41.

74 Cf. NOUWEN, 2017, p. 43.

75 Cf. BIANCU, 2012, p. 133.

76 Cf. BIANCU, 2012, p. 135.

77 "Jesús posee una insólita autoridad, que el pueblo percibe con asombro, que atrae, y que las autoridades consideran un peligro e intentan desacreditarle [...] No es una autoridad legal, porque Jesús no puede presentar nada que acredite sus conocimientos ni tiene estudios de escriba. Tampoco goza de una autoridad tradicional, la que podría conferirle el ser paterfamilias de una casa prestigiosa o pertenecer a un linaje al que se atribuye autoridad hereditaria (como era el caso con las familias sacerdotales). Podríamos decir que es una autoridad carismática, que hunde sus raíces en una experiencia profunda personal y encuentra eco en la gente, que percibe la autenticidad y ejemplaridad de esta vida", AGUIRRE, R. La mirada de Jesús sobre el poder. In: Teología y Vida, n. 55 (2014/1), p. 86-87. 
De fato, como bem assevera Schillebeeckx quando afirma que o problema do ministério sem o carisma corre o risco de reduzir-se a uma instituição de poder, pleno de autoritarismos e abusos, com uma série de desequilíbrios, indiferenças e de compromissos distantes da luz do mistério de Cristo. E o problema do carisma sem o ministério corre o risco de dissipar-se em exaltação, em fanatismo, em pura subjetividade, em conceitos eclesiais e espirituais em dissonância com a boa-notícia do Evangelho. ${ }^{78}$

Nessa perspectiva, a inteligência evangélica que muda a concepção de poder para a de autoridade pastoral compreende que a função ministerial não pode ser puramente uma delegação de baixo e nem mesmo uma espécie de delegação ad omnia do alto, como se na Igreja não houvesse o Espírito de discernimento para a operação e o serviço. Uma autoridade qualificada e evangélica deriva do próprio carisma do ministério. Esse ponto de partida pode nos ajudar a qualificar a necessidade de competência pastoral, pois não tendo uma reflexão de origem sacramental, pertencendo ao caráter, vem concebida como um poder que desce de cima por meio de determinações estruturadas e de faculdades frias. Essa origem, acreditando ser de origem imediatamente divina, confere à palavra de quem a detém, não uma autoridade ritual e real, mas uma faculdade que é garantia da verdade magisterial, jurídica e moral. Não sendo considerada a competência, avaliada pelo caminho de santidade e de maturidade, de discernimento à luz do Evangelho, existe somente o poder funcional, e pelo exercício de uma forma doentia de poder, esquece-se da necessidade de uma coerente forma de vida e da fidelidade a um programa espiritual, simbólico e ritual.

Dessa forma, o carisma deve constituir a competência do servo, qualificá-lo e torná-lo adequado para servir. Pode ser um serviço ocasional ou funções mais estáveis, necessárias para a vida e a missão da Igreja e pode ser um carisma simplesmente reconhecido na comunidade e regulado em seu exercício em vista do crescimento do corpo de Cristo.

Dado pelo Espirito Santo, o carisma tem em si os sinais de autenticidade, cuja interpretação e acolhimento dependem da comunidade. Assim sendo, a Igreja não cria seus ministérios, mas sabe-os recebidos do Espírito, acolhe-os e discerne as pessoas aptas ao seu exercicio. Infundindo um carisma, o Espírito cria também a função ministerial correspondente, para beneficio

78 Cf. SCHILLEBEECKX, E. Il ministero nella chiesa. Servizio di presidenza nella comunità di Gesù Cristo. 3. ed. Brescia: Queriniana, 1992. p. 38. 
de toda comunidade eclesial. A estrutura ministerial pressupõe os carismas e neles se fundamenta. Os ministérios externam e manifestam os carismas. Se a comunidade elege ou oficializa um candidato não significa que ela lhe outorgue o carisma ou ministério. Ela age, antes, na certeza de que o Espírito já se manifestou no candidato e que atua no processo comunitário de discernimento, reconhecimento e oficialização de um ministério. ${ }^{79}$

Por isso, voltar a valorizar a questão carismática contribuiria por demais para as ambiguidades que já foram sinalizadas no ministério sacramental da penitência. A questão do carisma para o exercício sacramental não pode ser somente um detalhe, sobretudo, naqueles sacramentos que estão ligados ao estado de vida cristã, à santidade do batizado-pecador e à humanidade da Igreja. Mas, como sabemos, por razões históricas e teológicas, a valorização do carisma não encontrou a sua direção exata no exercício do ministério. Inclusive, justifica-se que esse parece se opor, por uma parte, ao ministério, dando a este termo um significado ligado ao sacramento da ordem e, por outra parte, à instituição, dando um significado político e jurídico. ${ }^{80}$

Não tenhamos dúvidas de que uma forma de organização da comunidade eclesial a partir do carisma é capaz de evitar as formas de dominação e impedir que espíritos pouco evangélicos se apropriem privadamente do poder sagrado. Paulo bem o entendeu. ${ }^{81}$

\section{Conclusão}

Estamos certos de que as propostas que apresentamos diante da constatação de uma crise interna do sacramento da Ordem no exercício ministerial da penitência continuam abertas. O tema é amplo e problemático. E, como afirmamos desde o início, merece um ulterior e aprofundado trabalho. Não basta boa vontade! Como afirma a teóloga Stella Morra, "uma boa vontade sem competência no momento de crise pode produzir somente caos". ${ }^{82}$

Então qual é o nosso ministério? Ser sinal e instrumento para que eles se encontrem. Fique claro que não somos o pai, nem o pastor, nem o

\footnotetext{
79 WEIZENMANN, M. Os ministérios na Igreja. In: Teologia em questão, n. 32 (2017), p. 32.

80 Cf. LAFONT, 1998, p. 107-108.

81 Cf. BOFF, 1994, p. 256.

82 MORRA, 2015, p. 29.
} 
samaritano. Antes, como pecadores, estamos do lado dos outros três. $O$ nosso ministério tem de ser sinal e instrumento daquele encontro. Por isso, estamos situados no âmbito do mistério do Espirito Santo, que é quem cria a Igreja, quem faz a unidade, quem reaviva de cada vez o encontro. Outra coisa própria dum sinal e dum instrumento é a sua não autorreferencialidade. Ninguém fica no sinal, logo que compreendeu a significação; ninguém fica a olhar para a chave de fendas ou para o martelo, mas olha o quadro se ficou bem fixado. A essência do sinal e do instrumento é serem mediadores. Talvez esteja aqui a chave da nossa missão neste encontro da misericórdia de Deus com o homem [...] Um bom mediador é aquele que facilita as coisas e não coloca impedimentos. ${ }^{83}$

Sendo assim, a prospectiva que lançamos como possibilidade de uma releitura do ministério do confessor para favorecer a sua não improvisação, desfocando a crise do sacramento da penitência de uma leitura externa, é uma boa e imprescindível articulação entre o estilo ministerial de Jesus, a inteligência evangélica da estrutura de poder e a importância do Espírito na Igreja, permitindo passagens da questão do sinal dos sacramentos à uma boa vivência da graça que realiza conversão e transformação de vida.

\section{Referências}

AGUIRRE, A. La mirada de Jesús sobre el poder. Teología y Vida, n. 55 (2014/1), p. 83-104.

BATTOCCHIO, R. Note storiche e teologiche sul dibattito attorno alla distinzione fra potestas ordinis e potestas iurisdictionis. In: AUTORITÀ e forme di potere nella chiesa. Milano: Glossa, 2019. p. 125-154.

BELLI, M. Sacramenti tra dire e fare. Piccoli paradossi e rompicapi celebrativi. Brescia: Queriniana, 2018.

BIANCU, S. Il massimo necessario. L'etica alla prova dell'amore. Milano: Mimesis, 2020.

BIANCU, S. Saggio sull'autorità. Milano: EDUCatt, 2012.

BOFF, L. Igreja, carisma e poder. São Paulo: Ática, 1994.

BOGNER, C. Questa chiesa uccide. Disponível em: http://www.settimananews.it/chiesa/questa-chiesa-uccide. Acesso em: 9 set. 2020.

83 FRANCISCO. No Jubileu dos sacerdotes - terceira meditação, 2 jun. 2016. 
BORGMAN, E. Aspectos teológicos en la crisis de los abusos sexuales. In: Concilium, n. 344 (2012/1), p. 143-150.

BUSCA, G. La riconciliazione: tra crisi, tentativi di riforma e ripensamento. Lo stato attuale della riflessione teologico-pastorale. In: IL SACRAMENTO della penitenza. Milano: Glossa, 2010. p. 179-209.

CERTEAU, M. Autorités chrétiennes. In: Études, n. 332 (1970), p. 373-388.

D'AMBROSIO, R. Mutazione del potere nella società e nella Chiesa. In: ASSOCIAZIONE TEOLOGICA ITALIANA. Autorità e forme di potere nella chiesa. Milano: Glossa, 2019. p. 3-22.

FERRETTI, G. Il criterio misericordia. Sfide per la teologia e la prassi della Chiesa. Brescia: Queriniana, 2017.

FRANCISCO. Exortação Apostólica Evangelii gaudium, 2013.

FRANCISCO. Audiência geral, 20 nov. 2013.

FRANCISCO. Bula de proclamação de Jubileu da misericórdia Misericordiae vultus, 2015.

FRANCISCO. Carta por ocasião do centenário da Faculdade de Teologia da Pontifícia Universidade Católica Argentina, 3 mar. 2015.

FRANCISCO. No Jubileu dos sacerdotes - segunda meditação, 2 jun. 2016.

FRANCISCO. No Jubileu dos sacerdotes-terceira meditação, 2 jun. 2016.

FRANCISCO. Carta Apostólica Misericordia et misera, 2016.

FRANCISCO. Exortação Apostólica pós-sinodal Amoris Laetitia, 2016.

FRANCISCO. Discurso à I Congregação geral da XV Assembleia geral do Sínodo dos bispos sobre "os jovens, a fé e o discernimento vocacional", 3 out. 2018.

FRANCISCO. Discurso aos missionários da misericórdia, 10 abr. 2018.

FRANCISCO. Carta ao povo de Deus, 20 ago. 2018.

FRANCISCO. Exortação Apostólica Gaudete et exsultate, 2018.

FRANCISCO. Mensagem às Pontificias Obras Missionárias, 21 maio 2020.

GALAVOTTI, E. Giovanni XXXIII e l'età della misericórdia. In: Path, n. 17 (2018), p. 451-467.

GALLI, C. "Revolución de la ternura y reforma de la Iglesia". Medellín, n. 170 (2018), 75.

GRILLO, A. Grazia visibile, grazia vivibile. Teologia del sacramenti in genere ritus. Padova: Messaggero, 2008. 
GRILLO, A. Per un confronto aperto ed efficace tra teologi e canonisti sul matrimonio. Disponível em: http://www.cittadellaeditrice.com/ munera/per-un-confronto-aperto-ed-efficace-tra-teologi-e-canonisti-sul-matrimonio/. Acesso em: 9 set. 2020.

GRILlO, A. Um dissídio sobre autoridade, entre Agamben e Neri: direitos e deveres em conflito. Disponível em: http://www.ihu.unisinos. $\mathrm{br} / 78$-noticias/599278-um-dissidio-sobre-a-autoridade-entre-agamben-e-neri-direitos-e-deveres-em-conflito. Acesso em: 9 set. 2020.

LAFONT, G. Immaginare la Chiesa cattolica. Linee e approfondimenti per un nuovo dire e un nuovo fare della comunità cristiana. Cinisello Balsamo: San Paolo, 1998.

LAFONT, G. Storia teologica della chiesa. Itinerario e forme della teologia. Cinisello Balsamo: San Paolo, 1997.

LAFONT, G. La Chiesa: il travaglio delle riforme. Immaginare la Chiesa cattolica. Cinisello Balsamo: San Paolo, 2012.

LAFONT, G. Piccolo saggio sul tempo di papa Francesco. Bologna: Dehoniane, 2017.

LEBRA, A. Clericalismo. Disponível em: http://www.settimananews.it/ chiesa/clericalismo-2/. Acesso em: 30 set. 2020.

LEGRAND, H. Clericalismo e abuso sexual-por que tamanha inércia? Disponível em: http://www.ihu.unisinos.br/600353-clericalismo-e-abuso-sexual-por-que-tamanha-inercia. Acesso em: 9 set. 2020.

LIBANIO, J. A identidade e a espiritualidade do presbítero no processo de mudança de época. In: Perspectiva Teológica, n. 121 (2011), p. 353-388.

MICHAELDAVIDE, F. Preti senza battesimo. Una provocazione, non un giudizio. Cinisello Balsamo: San Paolo, 2018.

MICKENS, R. Os católicos ainda não entenderam: os abusos sexuais não têm a ver com sexo. Disponível em: http://www.ihu.unisinos.br/78-noticias/596635-os-catolicos-ainda-nao-entenderam-os-abusos-sexuais-nao-tem-a-ver-com-sexo. Acesso em: 9 set. 2020.

MORRA, S. La misericordia, (ri-)forma della chiesa. Una prospettiva strutturale. In: Concilium, n. 53 (2017/4), p. 56-66.

MORRA, S. Dio non si stanca. La misericordia come forma ecclesiale. Bologna: Dehoniane, 2015.

NOUWEN, H. Il guaritore ferito. Il ministero nella società contemporanea. 11. ed. Brescia: Queriniana, 2017. 
PEREIRA, W. Sofrimento psíquico dos presbiteros. Dor institucional. Petrópolis: Vozes, 2012.

PORTILLO, D. Igreja ainda não entendeu a seriedade do problema dos abusos sexuais. Disponível em: http://www.ihu.unisinos.br/78-noticias/594316-igreja-ainda-nao-entendeu-a-seriedade-do-problema-dos-abusos-sexuais. Acesso em: 9 set. 2020.

SCANONNE, J. La Ética Social del Papa Francisco. El Evangelio de la misericordia según el espíritu de discernimento. Teología, n. 126 (2018), 146.

SCHICKENDANTZ, C. Fracaso institucional de un modelo teológico-cultural de Iglesia. Factores sistémicos en la crisis de los abusos. Teología y Vida, n. 60 (2019/1), 9-40.

SCHILLEBEECKX, E. Il ministero nella chiesa. Servizio di presidenza nella comunità di Gesù Cristo. 3. ed. Brescia: Queriniana, 1992.

SCHONBORN, C. A chocante realidade dos abusos sexuais clericais. Disponível em: http://www.ihu.unisinos.br/78-noticias/594750-schoenborn-explica-a-chocante-realidade-dos-abusos-sexuais-clericais. Acesso em: 9 set. 2020.

SCHONBORN, C. Um espiral do silêncio está no cerne dos abusos sexuais clericais em curso. Disponível em: http://www.ihu.unisinos. br/590694-cardeal-schoenborn-uma-espiral-do-silencio-esta-no-cerne-dos-abusos-sexuais-clericais-em-curso. Acesso em: 9 set. 2020.

SPADARO, A. Intervista a papa Francesco. In: La Civiltà Cattolica, n. 3918 (2013), p. 449-467.

TARGONSKI, F. Il sacramento della penitenza in prospettiva antropologica. In: Miscellanea Francescana, n. 115 (2015), p. 451-467.

THEOBALD, C. Il coraggio di anticipare il futuro della Chiesa. In: Concilium, n. 54 (2018/4), p. 21-31.

WEIZENMANN, M. Os ministérios na Igreja. In: Teologia em Questão, n. 32 (2017), p. 11-37.

ZOLLNER, H. Onde dizem 'aqui não há abusos', significa somente que ali não se fala sobre isso. Há em todas as partes. Disponível em: http://www.ihu.unisinos.br/78-noticias/586636-onde-dizem-aqui-nao-ha-abusos-significa-que-ali-nao-se-fala-ha-em-todas-as-partes. Acesso em acesso: 9 set. 2020 . 